\title{
Influence of the material used to build the blades of a wind turbine on their starting conditions
}

\author{
Eugen-Vlad Năstase* \\ Technical University Gheorghe Asachi of Iaşi, Department of Fluid Mechanics, Fluid Machinery and \\ Fluid Power Systems, Iaşi, Romania
}

\begin{abstract}
Wind energy has been shown to be one of the most viable sources of renewable energy. Hydraulic machines that convert the energy of a fluid into mechanical energy are called turbines. A wind turbine is a device which extracts kinetic energy from the wind. With increasing energy demands is necessary to increase the size of wind turbines. Under these conditions the turbine will start only at high wind speeds. On the other hand, the control of high speed is more difficult and the reduction of the inertial forces becomes mandatory. This study presents an analysis of the material influence on the wind turbine starting conditions.
\end{abstract}

\section{Introduction}

Global energy consumption in the last decades has increased at a very rapid rate. Present trends in global population growth, rapid industrialization, and urbanization in major population centers of the world suggest that the world energy demand will continue to increase in the next years. A solution to this problem could be producing energy from renewable sources [1-3]. The main types of renewable energy is wind power, solar power, geothermal energy, hydropower and various forms of biomass. These sources have been coined renewable due to their continuous replenishment and availability for use over and over again. Compared to many other conventional energy sources, wind power's environmental effects are fairly minor [4]. Wind power does not release any toxic gas pollution into the atmosphere and does not consume any amount of fuel. The only energy that is used due to wind power is the energy used in actual construction of the wind power plant. The increase in power capability is produced by the increase in the rotor diameter [5], and hence the increase in the turbine inertia which in turn increases its response time to changes in wind speed [6]. This study is structured on 5 sections and presents an analysis of the material influence on the wind turbine starting conditions. Section 2 will present the diagram of energy transformation in a turbine and the main components for a wind turbine.

In Section 3, the design methodology of blade will be shown. In section 4 will be analyzed the drive train for a wind turbine and will be reported a modal analysis for three materials used in blade construction. Section 5 will present the conclusions of this study.

${ }^{*}$ Corresponding author: nastase_eugenvlad@yahoo.com 


\section{General consideration}

A turbine is a hydraulic machine that transform hydraulic energy of a fluid into mechanical energy. The block diagram which shows the transformation of hydraulic energy (load $\mathrm{H}$ and flow Q) into mechanical energy (torque $\mathrm{M}$ and angular velocity $\omega$ ) is shown in Figure1.

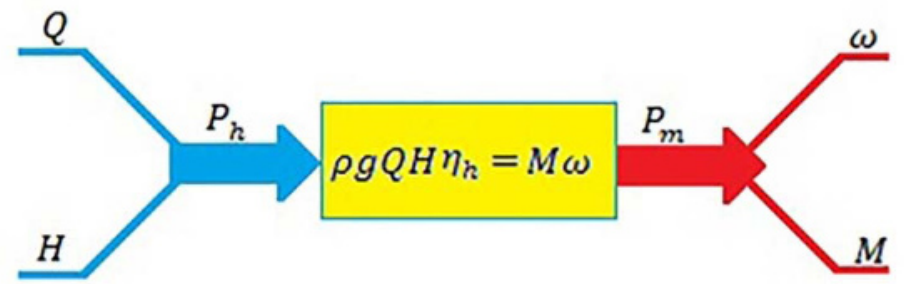

Fig. 1. Block diagram of the energy transformation in turbine.

Most modern wind turbines are built with a horizontal-axis similar to the one seen in the Figure 2. The hub and the blades of the wind turbine are constructed with an aerodynamic design and when interacting with the wind the rotor begin to spin. The turbine shaft spins with the blades and is the mechanism that transfers the rotational/mechanical energy of the blades towards the electrical generator. Generally for increase the rotational speed of the turbine shaft is used a gearbox.

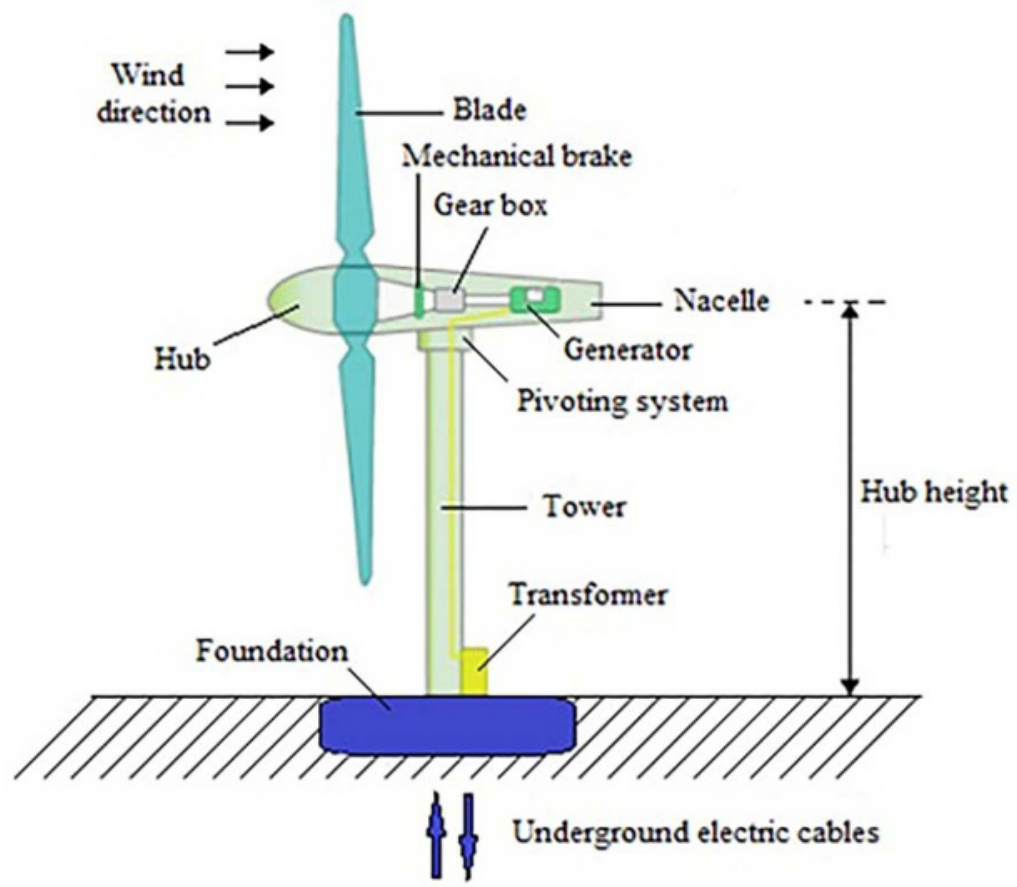

Fig. 2. Overview of main components for a wind turbine.

The generator converts the mechanical energy from the wind into electrical energy. The turbine tower contains wiring so the generator can send electricity into a transformer or a battery which will eventually distribute usable electric power. A brake is installed to prevent mechanical failure from high wind [7]. 


\section{Design methodology of blade}

Aerodynamic performance is fundamental for efficient rotor design. Aerodynamic lift is the force responsible for the power yield generated by the turbine and it is therefore essential to maximise this force using appropriate design. A resistant drag force which opposes the motion of the blade is also generated by friction which must be minimised.

The methodology used for aerodynamic calculations is the Blade Element Momentum Method. The fundamental components of the rotor are the blades [1, 8, 9]. They are the devices that convert the force of the wind into the torque needed to generate useful power.

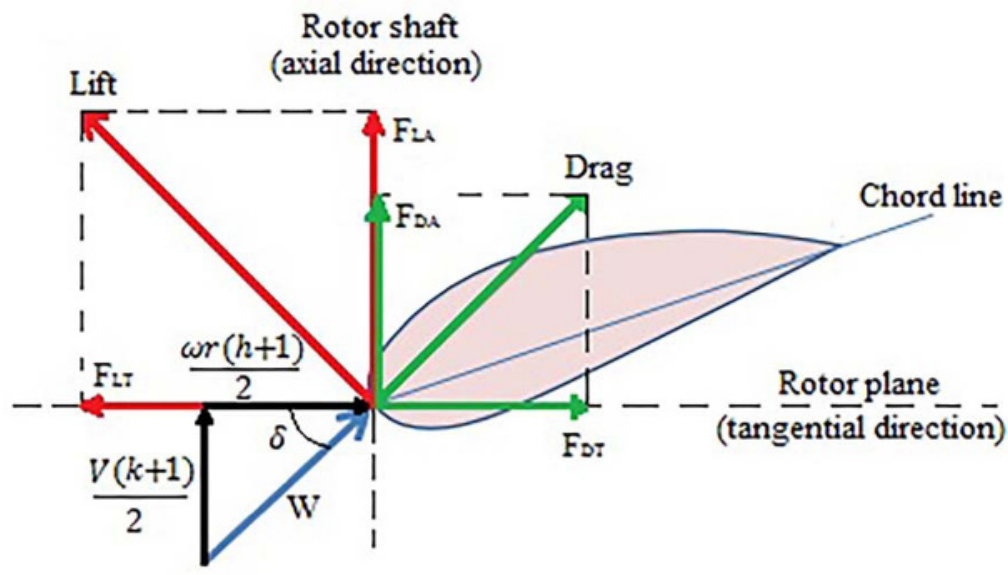

Fig. 3. Components of force and velocity in the blade cross-section.

The essence of this method is to divide the turbine blade into a finite number of crosssections. The finite blade length between the two nearest cross-sections is called the blade element. The relative angles of attack and consequently the induction factors and incidences are found for each blade cross-section and averaged for the elements. The found measures allow the calculation of the aerodynamic efficiency, lift and drag forces and coefficients [10]. By designing the lift force and drag force on axial and tangential direction are obtained elementary forces (Figure 3):

$$
\begin{aligned}
& F_{A}=F_{L A}+F_{D A} \\
& F_{T}=F_{L T}-F_{D T}
\end{aligned}
$$

Where $F_{A}$, is the elementary force on the axial direction and $F_{T}$ is the elementary force on the tangential direction. Tangential component is that which gives elementary torque. In Figure 3 also can be seen velocity triangle for a wind turbine. This triangle is formed by the decomposition of $\boldsymbol{W}$ velocity in the horizontal direction and in the tangential direction. The axial velocity and the tangential velocity are affected by $h$ and $k$ coefficients. These coefficients take into account the induced rotation of the airflow which goes through the rotor provoked by the sheet of vortices originated at the tip and the hub of the finite blade.

For a given situation, specifically for an average wind speed, $\mathrm{V}=7 \mathrm{~m} / \mathrm{s}$ and a rotor diameter $\mathrm{D}=5,8 \mathrm{~m}$, was made aerodynamic blade computing. In these conditions it was calculated the blade in ten sections, as can be seen in Figure 4.a. 3D model of blade, presented in Figure 4.b, was obtained uniting the ten sections using Catia software. Other method to change dynamic and mechanical properties of wind turbine is modifying the material, which the blade is made of [9]. 


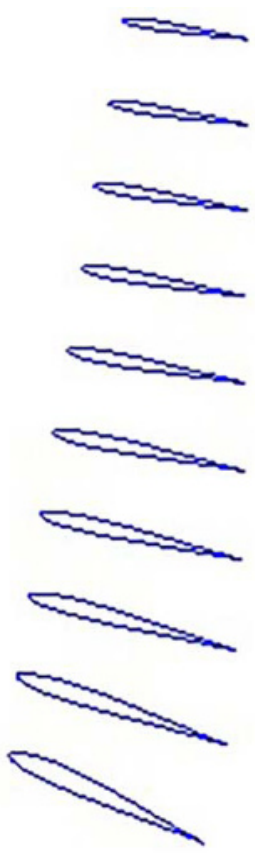

a)

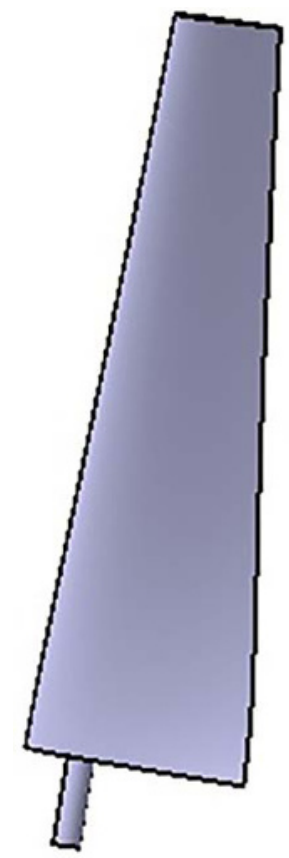

b)

Fig. 4. The blade of wind turbine ( $\mathrm{a}$-profile layout in sections; $\mathrm{b}-3 \mathrm{D}$ model).

\section{Kinematic chain for wind turbines}

The energy conversion chain is organised into four subsystems (as can see in Figure 5): aerodynamic subsystem, consisting mainly of the turbine rotor, which is composed of blades, and turbine hub, which is the support for blades; drive train, generally composed of: low-speed shaft - coupled with the turbine hub, speed multiplier and high-speed shaft driving the electrical generator .

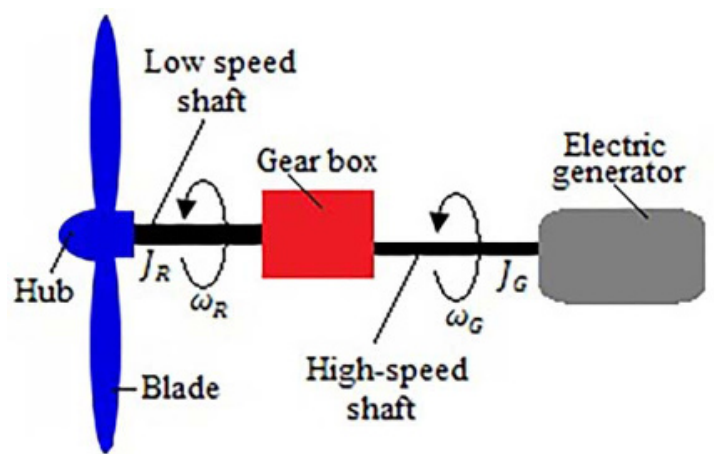

Fig. 5. The diagram of the drive train.

After the analysis of the diagram presented in Figure 5, we can write the equations of equilibrium:

$$
M_{R}-M_{G B i}=J_{R} \frac{d \omega_{R}}{d t}+B_{R} \cdot \omega_{R}
$$




$$
M_{G B e}-M_{G}=J_{G} \frac{d \omega_{R}}{d t}+B_{G} \cdot \omega_{G}
$$

Where:

- $\quad B_{R}$ and $B_{G}$ are the constant friction in the rotor and generator system;

- $M_{R}$ is the rotor torque;

- $M_{G B i}$ is the gear box torque to the start;

- $M_{G B e}$ is the gear box torque to the end;

- $M_{G}$ is the generator torque to the end;

- $J_{R}$ is the moment of inertia of the rotor;

- $J_{G}$ is the moment of inertia of the generator;

- $\omega_{R}$ is the rotational speed of the main shaft;

- $\omega_{G}$ is the rotational speed to the start of generator.

From (3) result:

$$
\frac{d \omega_{R}}{d t}=\frac{M_{R}-M_{G B i}-B_{R} \cdot \omega_{R}}{J_{R}}
$$

The moment of inertia of the rotor for a wind turbine with $n$ blades [11] is given by:

$$
J_{R}=n \cdot m \cdot r_{i}^{2}
$$

Where, $n$ is the number of blades, $m$ is the mass of one blade, and $r$ is the radius of weight centre of blades. After analysis of relations (5) and (6) we can draw the following conclusion : importance of decreasing moment of inertia of rotor hence its inertial mass, will lead directly to increase rotational speed of main shaft so will enable faster start at low speed wind of power plant.

One of possible way to reduce the moment of inertia is given by reducing weight of blades. Wind turbinie blades have been made from a variety of materials that range from wood to metals to composites. The key structural design requirements for the turbine's blades are: must be strong to resist the extreme loads, must be stiff to prevent collision with the tower, must be as light as possible to minimize the cost and the starting, and should be stiff and light to avoid resonance.

These requirements require the use of materials with high stiffness properties to withstand a long time of service and extreme loads and respectively a low density is needed to reduce centrifugal and gravitational forces. For the modal analysis, we considered three materials, more exactly blade made of steel, aluminum and epoxy-carbon. After designing the blade in the Catia software, this is imported into Ansys and based on the geometry and properties of the material, the mass of the blade is computed and values for the three materials considered is given in Table 1.

Table 1. Mass of the blade for the three materials.

\begin{tabular}{|c|c|c|c|}
\hline Material & Steel & Aluminum & $\begin{array}{l}\text { Epoxy } \\
\text { carbon }\end{array}$ \\
\hline $\begin{array}{c}\text { Mass of blade } \\
(\mathrm{Kg})\end{array}$ & 685.37 & 241.85 & 139.69 \\
\hline
\end{tabular}

The modal analysis for the blade is executed by ANSYS Workbench [12] and the results is presented in Figure 6. 


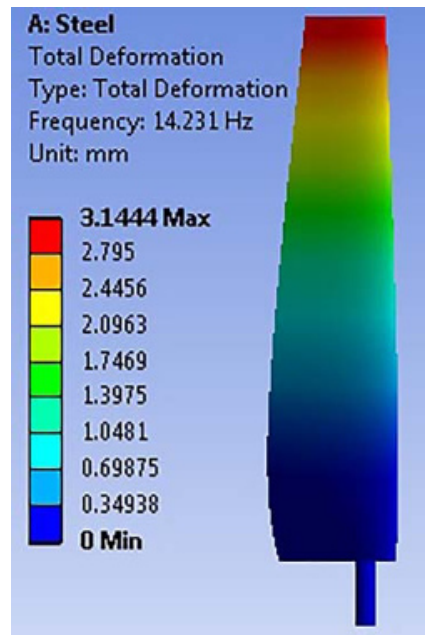

a)

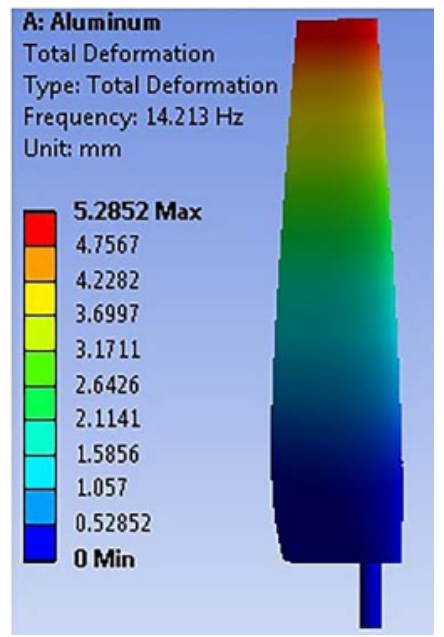

b)

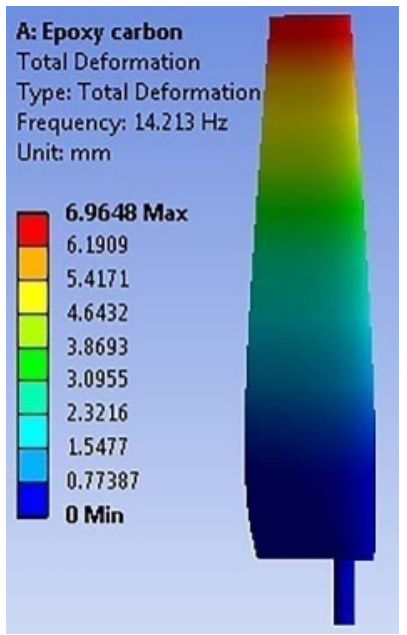

c)

Fig. 6. The diagrams of the modal analysis.

\section{Conclusions}

Wind power is an important source of renewable energy and plays a significant role in the world energy policy.

With increasing demand for renewable energy it is necessary to increase the dimensions of the rotors, which leads to the increase of the inertial masses.

Importance of decreasing moment of inertia of rotor hence its inertial mass, will lead directly to increase rotational speed of main shaft so will enable faster start at low speed wind of power plant.

After building the blades using the three materials and calculating the masses, one can conclude that the optimal solution is for the Epoxy-carbon blade.

Taking into account the inertial mass and after modal analysis performed on the blade in the three situations it can be concluded that the situation most favorable is for Epoxycarbon.

Composites materials are ideal for producing wind turbine blades because of their low weight and the mechanical properties needed for any blade design.

\section{References}

1. T.M. Asif, P. K.Yadav, IJESRT 4 (8), 326-332 (2015)

2. M. Chandrala, A. Choubey, B. Gupta, IJERA 2, 1244-1248 (2012)

3. W.T. Chong, K.C. Pan, S.C. Poh, A. Fazlizan, C.S. Oon, A. Badarudin, N. NikGhazali, Renew. Energy 51, 388-397 (2013)

4. V. Anbarasan, S. Eswaran, IJMERR 4 (1), 286-291 (2015)

5. A.S. Rathore, S. Ahmed, IJEST 3, 7975-7980 (2011)

6. U. Jassmann, M. Reiter, D. Abel, IFAC 6, 10107-10112 (2014)

7. V. M. Kumar, B. N. Rao, Sk. Farooq, IJAER 11 (6), 4491-4499 (2016)

8. T. Chuamvarasart, C. Chantharasenawong, S. Wongkittirat, ACEM14, 10 (2014)

9. T. Nitin, N.D. Mittal, A. Siraj, IJAER 1, 500-507 (2010)

10. I. Curtu, I.Teșulă, M.D. Stanciu, P. Piscoi, A. Savin, Pro Ligno 11, 157-164 (2015)

11. S. Barabas, F. Sarbu, B. Barabas, A. Fota, WASET 9, 878-881 (2015)

12. P. Lengvarský, J. Bocko, M. Hagara, AJME 1, 271-275 (2013) 